\section{International Scientific Journal Theoretical \& Applied Science}

\author{
p-ISSN: 2308-4944 (print) e-ISSN: 2409-0085 (online) \\ Year: $2014 \quad$ Issue: 12 Volume: 20 \\ Published: $30.12 .2014 \quad$ http://www.T-Science.org
}

\section{Sergey Alexandrovich Mishchik}

Associate Professor,

Candidate of Pedagogical Science,

Assistant professor Department of Physics, State Maritime University Admiral Ushakov, Russia sergei_mishik@mail.ru

SECTION 21. Pedagogy. Psychology. Innovation in Education.

\title{
STAR ERTSGAMMY - PHYSICAL AND MATHEMATICAL MODEL INTEGRITY-SYSTEM ABILITY TO LIVE
}

Abstract: Suggested physical and mathematical modeling of a holistic system of life-through the use of twelvepointed star as the lead Ertsgammy morphogenetic processes regarding psychological and pedagogical activity theory, psychological and pedagogical system analysis and the theory of the formation of mental actions.

Key words: pedagogometrika, consistency, integrity, stakeholders, personality analysis, twelve star Ertsgammy, the adjustable steam.

Language: Russian

Citation: Mishchik SA (2014) STAR ERTSGAMMY - PHYSICAL AND MATHEMATICAL MODEL INTEGRITY-SYSTEM ABILITY TO LIVE. ISJ Theoretical \& Applied Science 12 (20): 57-60. doi: http://dx.doi.org/10.15863/TAS.2014.12.20.13

\section{УДК 372.851}

\section{ЗВЕЗДА ЭРЦГАММЫ - ФИЗИКО-МАТЕМАТИЧЕСКАЯ МОДЕЛЬ ЦЕЛОСТНО-СИСТЕМНОЙ ЖИЗНЕДЕЯТЕЛЬНОСТИ}

Аннотация: Предложено физико-математическое моделирование ичелостно-системной жизнедеятельности через применения двенадцати конечной звезды Эригаммы в качестве ведущего формообразовательного процесса относительно психолого-педагогической теории деятельности, психолого-педагогического системного анализа и теории формирования умственных действий.

Ключевые слова: педагогометрика, системность, целостность, субъект деятельность, личность, анализ, двенадиать, звезда Эригаммы, образовательая пара.

Выделенные проблемы математического моделирования педагогометрических задач: педагогометрика и математическое моделирование учебной деятельности; моделирование учебной деятельности методами математической логики; математическое моделирование целостно-системного цикла жизнедеятельности - первая задача педагогометрики; математическое моделирование целостно-системного учебного действия - вторая задача педагогометрики; математическое моделирование целостносистемной коммуникативной деятельности третья задача педагогометрики; математическое моделирование целостно-системного субьекта деятельности - четвёртая задача педагогометрики и рассмотренные в априори последующие задачи педагогометрики определят дальнейшее развитие психологической теории деятельности, психолого-педагогического системного анализа и теории формирования интеллекта, а также методов их математического моделирования и всей педагогометрики в целом $[1 ; 2 ; 3]$.

Однако для синергетического развития выделенных проблем необходимо построение физико-математического образа определённых задач. Можно рассматривать любые формы представления данных процессов: от механических до облочных технологий, однако механическая модель позволит лучше представить установленные закономерности. Известно одно из классических определений механики как искусстве опускания Бога на Землю. Это составляло кульминационный эффект 
любого древнегреческого театрального спектакля, когда с помощью различных искусственных приспособлений на сцену опускался соответствующий образ Бога и развитие этих технических средств в дальнейшем и определило базисный смысл механики как особенной науки.

Количественный анализ числа структурных элементов циклических процессов жизнедеятельности, психолого-педагогического системного анализа, теории формирования интеллекта указывает на конкретную определённость этой меры - двенадцать (12) элементов. В целостно-системном цикле жизнедеятельности выделяются следующие целостно-системные элементы: 1) начальный субъект; 2) обобщённая деятельность; 3) средства деятельности; 4) технологическая деятельность; 5) предмет деятельности; 6) контрольная деятельность; 7) результат (продукт) деятельности; 8) ритуальная деятельность; 9) опредмеченная потребность; 10) восходящая деятельность; 11) компаунд-субъект; 12) развивающая деятельность. Результатом этой деятельности является супер-субъект, который открывает последующий цикл развития субъекта жизнедеятельности.

Количественное представление психологопедагогического системного анализа также актуализирует двенадцать (12) системных действий: 1) выделить объект изучения как систему; 2) определить порождающую среду; 3) установить целостные свойства предмета; 4) представить уровни анализа системы; 5) выделить структуру уровня; 6) определить структурные элементы уровня; 7) установить системообразующие связи уровня; 8) представить межуровневые связи объекта; 9) выделить форму организации предмета; 10) определить системные свойства объекта; 11) установить поведение предмета; 12) представить прогноз развития объекта. Выделенная совокупность системных действий составляет определённую «Азбуку Жизни» [5; 6; 7].

Анализ базисных основ теории формирования интеллекта в условиях целостносистемной жизнедеятельности устанавливает двенадцать (12) этапов формирования интеллекта:

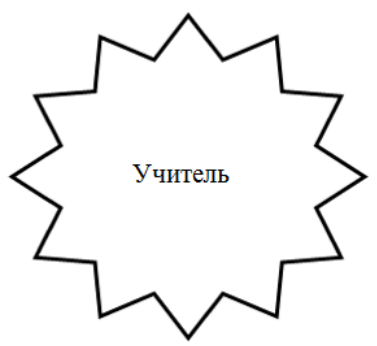

1) целостно-системная ориентационность;

2) целостно-системная мотивационность;

3) целостно-системная визуальность;

4) целостно-системная акустичность;

5) целостно-системная калориметричность;

6) целостно-системная термодинамичность;

7) целостно-системная обонятельность;

8) целостно-системная материальность;

9) целостно-системная рецепторность;

10) целостно-системная речистость;

11) целостно-системная письменность;

12) целостно-системная духовность.

Установленное множество этапов формирования интеллекта соответствует всем формам восприятия информации об окружающем Мире.

Совместное сочетание психологической теории деятельности, психолого-педагогического системного анализа и теории формирования интеллекта в различных соотношениях создают разнообразные формы и структуры жизнедеятельности, соответствующие им системы воспитания и образования, а также результаты данных процессов: от индивидуума до личности; от «частичного» специалиста до широкопрофильного. Одним из характерных признаков взаимодействий данных процессов в условиях жизнедеятельности является передача жизненного опыта между поколениями, когда выполняются «субъектно-предметносубъектные» отношения в условиях общения, обучения и практической деятельности. Ведущими глаголами учебно-профессиональной деятельности можно считать: формировать, грузить, давить, вставлять (мозги), крутить (ученика) и т.д. в зависимости от условий образовательного пространства [7; 8; 9].

Наиболее приемлемой формой модельного эффективного партнёрства «учитель-ученик» является вращение, то есть возникает вращательная пара с максимальной связью между ними - зубчатая дидактическая передача, в которой отражаются выделенные глаголы с максимальной эффективностью. Таким образом, формообразователем процесса развития жизнедеятельности является двенадцати конечная звезда - звезда Эрцгаммы: из языка древней египетской народности коптов эрц означает число 12, а гамма - гармонию.

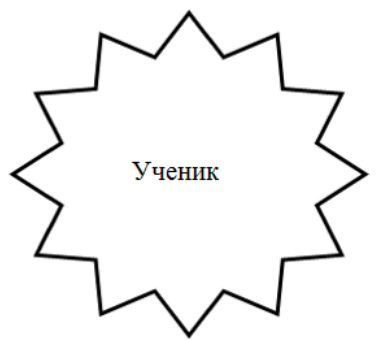

Рисунок 1 - Пара звезд Эрцгаммы. 
Из истории религии известно, что на небосводе в Вифлееме под озарением двенадцати конечной звезды появился Спаситель новорожденный Иисус и эта звезда в христианстве считается символом Иисуса и Его 12 учеников.
В нашей физико-математической модели можно выделить три основных вида звезды Эрцгаммы: звезда -- жизнедеятельность; звезда системный анализ; звезда - этап формирования интеллекта, которые выполняют различные роли.
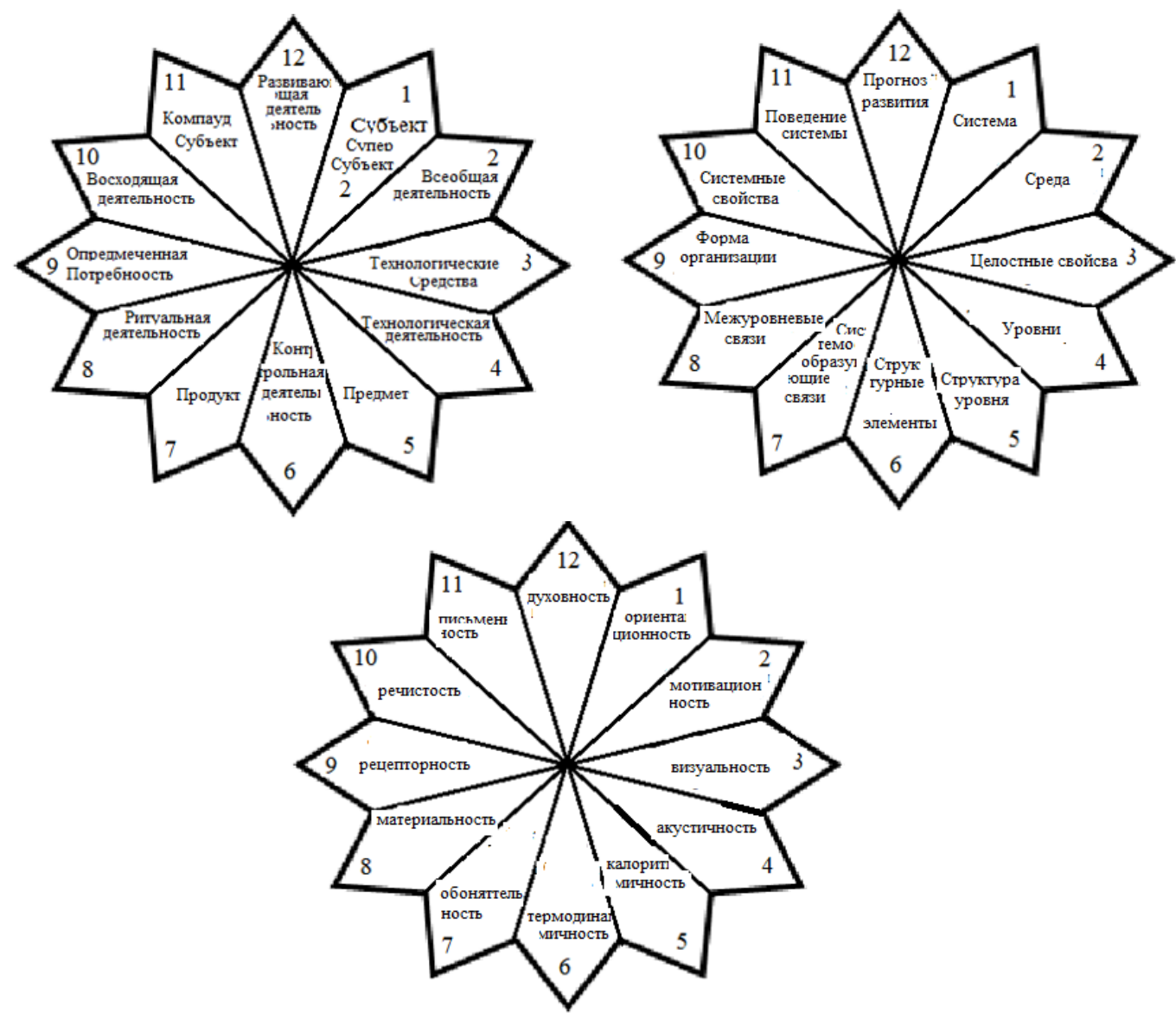

Рисунок 2 - Виды целостно-системных звёзд Эрцгаммы.

Основное требование при проектировании моделей зубчатых дидактических механизмов заключается в том, чтобы передача в любое время и на любых режимах учебной работы обеспечивала непрерывную передачу вращения от одного образовательного элемента к другому. При этом в зубчатых дидактических механизмах всегда должно обеспечиваться постоянство передаточного отношения информации. Постоянное передаточное отношение в зубчатом дидактическом механизме обеспечивается за счет правильного подбора профилей соприкасающихся поверхностей, отражающих ориентировочную, исполнительную и контрольную части формируемого учебнопрофессионального знания. Условия определяет теорема дидактического взаимодействия: общая нормаль, проведенная через точку касания двух профилей образовательного пространства, делит межсубъектное расстояние на части, обратно пропорциональные угловым скоростям формирования знания, т.е.:

$$
i_{12}=\frac{\omega_{1}}{\omega_{2}}=\frac{O_{2} W}{O_{1} W}=\text { const }
$$

Профили образовательных субъектов, удовлетворяющие требованию основной теоремы дидактического взаимодействия, устанавливают условие сопряжённости. В зависимости от решаемых дидактических задач необходима разработка специальной эвольвентной образовательной поверхности, которая обеспечивает эффективное предметнодеятельностное взаимодействие образовательной пары, Через коммуникативные звёзды Эрцгаммы моделируется целостно-системное образовательное пространство, направленное на формирование специалистов с заданными характеристиками. При этом можно задавать различные режимы дидактического взаимодействия и применять математическое 
моделирование методами гармонических функций, отражающих вращающий характер педагогометрических параметров. Главными образовательными моделями вращательных технологий следует считать пространственное проектирование знаний, отражающих системный тип ориентировки, формируемый дидактической фрезой звезды Эрцгаммы относительно смыслообразования многомерного цикла целостно-системной жизнедеятельности.

\section{References:}

1. Mishchik SA (2014) Pedagogometrika and mathematical modeling educational activity. /C.А.Мищик // Materialy Mezhdunarodnoy nauchnoy konferenctsii "Modern mathematics in science" - 30.06.2014. ISJ Theoretical \&Applied Science 6(14): 54-56. Caracas, Venezuela. doi:

http://dx.doi.org/10.15863/TAS.2014.06.14.10

2. Mishchik SA (2014) Simulation training activity methods of mathematical logic. /C.А.Мищик // Materialy Mezhdunarodnoy nauchnoy konferenctsii "Eurapean Science and Education" - 30.07.2014. ISJ Theoretical \&Applied Science 6(15): 72-74. Marseille, France. doi:

http://dx.doi.org/10.15863/TAS.2014.07.15.13

3. Mishchik SA (2014) Mathematical modeling system integrity-cycle of life activity - first goal pedagogometriki. /С.А.Мищик // Materialy Mezhdunarodnoy nauchnoy konferenctsii "European Applied Sciences" 30.08.2014. ISJ Theoretical \&Applied Science 7(16): 77-79. Aix-en-Provence, France. doi: http://dx.doi.org/10.15863/TAS.2014.08.16.13

4. Mishchik SA (2014) Mathematical modeling system integrity-curricular activities - the second problem pedagogometriki. /C.А.Мищик // Materialy Mezhdunarodnoy nauchnoy konferenctsii "European Innovation" 30.09.2014. ISJ Theoretical \&Applied Science 9(17): 126-128. Martigues, France. doi: http://dx.doi.org/10.15863/TAS.2014.09.17.21

5. Mishchik SA (2014) Mathematical modeling holistic-systemic communicative activity - the third task pedagogometriki. /C.А.Мищик // Materialy Mezhdunarodnoy nauchnoy konferenctsii "European Scientific
Achievements" - 30.10.2014. ISJ Theoretical \&Applied Science 10(18): 45-47. Brighton, UK. doi:

http://dx.doi.org/10.15863/TAS.2014.10.18.11

6. Mishchik SA (2014) Mathematical modeling integrity - system performance subject - fourth task pedagogometriki. /С.А.Мищик // Materialy Mezhdunarodnoy nauchnoy konferenctsii "Eurapean Science and Technology" - 30.11.2014. ISJ Theoretical \&Applied Science 11(19): 51-54 Southampton, UK. doi:

http://dx.doi.org/10.15863/TAS.2014.11.19.10

7. Tokmazov GV (2014) Matematicheskoe modelirovanie $\mathrm{V}$ uchebno-professional'noy deyatel'nosti. Materialy Mezhdunarodnoy nauchnoy konferentsii «Modern mathematics in science» - 30.06.2014. ISJ Theoretical \& Applied Science 6(14): 44-46. - Caracas, Venezuela. doi:

http://dx.doi.org/10.15863/TAS.2014.06.14.8

8. Tokmazov GV (2014) Analysis says study skills in the study of mathematics. Materialy Mezhdunarodnoy nauchnoy konferenctsii "Eurapean Science and Education" 30.07.2014. ISJ Theoretical \&Applied Science 6(15): 72-74. Marseille, France. doi: http://dx.doi.org/10.15863/TAS.2014.06.14.

9. Tokmazov GV (2014) Mathematical modeling research skills in educational activity methods of probability theory. Materialy Mezhdunarodnoy nauchnoy konferenctsii "European Science and Technology" 30.11.2014. ISJ Theoretical \&Applied Science 11(20): 66-69. Southampton, United Kingdom. doi:

http://dx.doi.org/10.15863/TAS.2014.11.19.13 